\title{
Chapter 8 \\ Tracing Technoscientific Collectives in Synthetic Biology: Interdisciplines and Communities of Knowledge Application
}

\author{
Alexander Degelsegger-Márquez
}

\subsection{Introduction: Technoscientific Communities?}

Scientific work is collective work. As scientists, we are trained in collective environments. We work and live in departmental and laboratory settings. We collaborate in teams, locally and remotely. We participate in conferences and publish in journals related to our field of work. We relate to colleagues in a specific discipline or an interdisciplinary field of research. We feel part of a scientific community. Or do we?

Scientific communities (in plural) have been defined as collectives that are based on knowledge, more concretely on a common way of producing scientific knowledge (Böhme 1974; Gläser 2006). Mathematicians have a different way of going about scientific knowledge production than biologists, molecular biologists a different one from zoologists. Acquiring the appropriate ways of producing knowledge is an integral part of a young scientist's education and socialisation. Belonging to a scientific community, one could argue, is part of a scientists' identity.

The relevance of such a concept of scientific community has long been contested, however, in parts of STS literature. Already at the end of the 1970s, the role of scientific communities in knowledge production as well as their importance for scientists' subjectivities was questioned (Whitley 1978; Knorr-Cetina 1981). It was suggested, for instance, that the more immediate laboratory and collaboration environment plays a much more decisive role than the diffuse layer of scientific communities.

The question of the relevance of scientific communities gains new momentum in an environment where research funding is increasingly mission-driven and application-oriented, trying to identify the 'next big thing' in terms of economic

\footnotetext{
A. Degelsegger-Márquez ( $\square)$

Gesundheit Österreich GmbH, Vienna, Austria

e-mail: alexander.degelsegger@goeg.at

(C) The Author(s) 2021

K. Kastenhofer, S. Molyneux-Hodgson (eds.), Community and Identity in

Contemporary Technosciences, Sociology of the Sciences Yearbook 31,

https://doi.org/10.1007/978-3-030-61728-8_8
} 
potential. Decision-makers do not only choose certain thematic areas over others when distributing funding. They increasingly aim at establishing or nurturing scientific communities in a strategic manner (Kastenhofer 2018). How researchers and their practices relate to these efforts is an unresolved question.

One field that received significant policy-level attention in recent years is synthetic biology. Synthetic biology is about bringing engineering principles (like abstraction, modularity, or standardisation) into biology (cf. European Commission 2005). Synthetic biologists think about living organisms as devices that can be designed to perform specific functions, e.g. produce drugs or detect toxins. Its proponents and critics alike argue that this profoundly changes the way biological research is done.

According to social scientists following and reflecting on the field, synthetic biology spans visions of understanding nature and engineering life (Kastenhofer 2013) or, in other words, of comprehension and construction (O'Malley et al. 2007). Synthetic biology does not aim at representing nature but at remaking it. In doing so, it potentially changes our understanding of what 'natural' means (Calvert 2010).

While both the label and the practices of synthesising or engineering living organisms go back to the early twentieth century, contemporary synthetic biologists themselves relate their work to practices in the early 2000s located in interdisciplinary laboratories in the US (cf. Benner and Sismour 2005; Endy 2005). Since then, synthetic biology has received significant funding in the US and in parts of Europe and Asia.

Three aspects make synthetic biology a particularly interesting case to restate the question of the relevance of scientific communities. First, synthetic biology can be described as a technoscientific field of research (cf. Schmidt et al. 2010) where boundaries between scientific knowledge production and technological applications are blurred (Nordmann 2011; Kastenhofer 2009). The case helps to better understand a potential related blurring of boundaries between scientific communities. Secondly, in integrating biology and engineering, synthetic biology engages researchers with very distinct epistemic orientations. The notion of interdiscipline (Jacobs and Frickel 2009) has been proposed to study the emergence of disciplinary hybrids like synthetic biology. The case helps us to understand how we can conceive of interdisciplinary scientific communities in contrast to disciplinary scientific communities. ${ }^{1}$ Thirdly and finally, synthetic biology can be considered a field in ongoing emergence (Morrison 2012) with slightly divergent origin stories, competing visions regarding its present condition, and the continuous construction of promissory narratives. Given that the field is not stabilised, the mechanisms of community constitution are empirically accessible and can be productively researched in contexts of emergence.

\footnotetext{
${ }^{1}$ I propose to differentiate disciplines from scientific communities in that the former are a specific form of the latter: disciplines are, in concrete terms, disciplinary scientific communities. This definition builds on Marcovich and Shinn (2011) who understand disciplines as 'well-defined and differentiated epistemological and organizational units ... and institutional ... bodies that are separated by recognized boundaries' (p. 586).
} 
I thus set out to study the role scientific communities play in synthetic biology as a technoscientific, interdisciplinary hybrid. What are the communities that matter? Is there something distinctive about the synthetic biology case that points to specificities of technoscientific communities? I address these questions from two angles: first, I review community-making efforts in synthetic biology. Both the top-down side (i.e. the public funding mobilised) and the bottom-up initiatives from researchers are important here. Secondly, I take challenges in synthetic biology research collaborations as an empirical entry point to studying community dynamics. Before approaching my empirical material, I will review key concepts in the sociological study of scientific communities.

\subsubsection{From Community to Scientific Community}

In sociological theory, the concept of community is linked to authors like Ferdinand Tönnies, Max Weber, or Talcott Parsons. Tönnies (1887/2001) first defined community as such and contrasted the concept with that of society. Communities are characterised by social ties that build on personal social interactions, roles, values, and corresponding beliefs (ibid., pp. 22ff). Decision-making in communities is consensual. Individuals are born into communities and the latter encompass all their actions and relations. In Weber's words, the orientation of social action in 'communal' social relationships is 'based on a subjective feeling of the parties, whether affectual or traditional, that they belong together' (Weber 1921/1978, p. 40). The conceptual opposite of community ('Gemeinschaft') is society ('Gesellschaft'). 'In Gemeinschaft [groups of people] stay together in spite of everything that separates them; in Gesellschaft they remain separate in spite of everything that unites them' (Tönnies 1887/2001, p. 52).

Following Tönnies and Weber, Talcott Parsons also distinguished between community and society. This distinction results from five so-called pattern variables (cf. Parsons and Shils 1951) between which, according to Parsons' structural functionalism, each actor must choose in a given situation of agency. According to these dichotomous variables, communities are characterised by affectivity (vs affective neutrality), functional diffuseness in the definition of situations (vs functional specificity), particularism (vs universalism), ascription (vs achievement), and collectivity orientation (vs self orientation). Applying these traditional sociological approaches to conceive of scientific communities is not without tensions.

Concepts of scientific community are typically connected to characteristics that, according to sociological tradition, resemble societies more than communities. Merton (1942/1993) delineated a joint scientific ethos and thereby focused on the norms shared within the scientific community at large, taking the latter for granted as both result and source of this joint ethos. Science as a field of collective human activity is, in his perspective, characterised by universalism, communalism (in the sense of common ownership), disinterestedness, and organised scepticism (ibid.). 
Interestingly, all but one (communalism) of these Mertonian values stand against the traditional sociological definitions of community.

With the practice turn in STS, however, the relevance of Mertonian norms in practices of scientific knowledge production has been questioned. Laboratory studies (e.g. Knorr-Cetina 1981) bring scientific practices closer to traditional ideas of community, pointing to, for instance, the relevance of place (e.g. specific laboratory settings) or affectivity. Values are not something external to scientific practices and discourses. They do not inform or orient these practices but are generated within them (Swidler 2001). Maybe it is because of these tensions with traditional sociological accounts that the notion of scientific community made its way into the sociology of science through the backdoor.

\subsubsection{Scientific Communities}

The notion of scientific communities was introduced into the sociology of science by Thomas Kuhn (1962/2002) and Karl Polanyi (1962). ${ }^{2}$ It was somewhat secondary to their work, however, and therefore undertheorised (cf. Gläser 2006, p. 46). Böhme (1974) was the first to offer a more thorough definition. He defines scientific communities as being based on knowledge (as opposed to values). Scientists coordinate their action through a common object (the research subject, topic or method, etc.). At the core of scientific communities is the organising principle of argumentation: scientific communities constitute arenas for scientists to discuss knowledge claims. Members of a scientific community are not defined by the norms they share (as they might be in a Mertonian view of science) but by the way in which they produce knowledge.

The understanding of scientific communities as defined by shared practices rather than shared values is taken up by later theoretical work. The shared practice described as the basis of scientific communities is the production of scientific knowledge (Holzner and Marx 1979). Gläser (2006) conceptualises communities of scientific knowledge production as the mode of social organisation that allows scientists to produce the specific kind of knowledge that is scientific knowledge. Collective concerted production is structured through a common object and rests on autonomous, decentralised decisions of the producers working the object. Production communities hence solve the problem of motivation, information, and integration in different ways than markets, organisations, or networks would. They are, thus, a distinct type of social order. With this characterisation, Gläser refines the argument that scientific communities are defined by the way in which they produce knowledge: they are characterised by work on a common object and forms of organisation that allow for decentralised knowledge production.

\footnotetext{
${ }^{2}$ Of course, Fleck's (1935/1981) concept of thought collectives and their role in the construction of scientific facts already pointed in the direction of scientific communities.
} 
There are, however, different approaches to refining our ideas of scientific communities. Meyer and Molyneux-Hodgson (2010), for instance, draw our attention not only to the production of knowledge but also to its dissemination. Elzinga (1993) distinguishes disciplinary epistemic communities from hybrid epistemic communities. While the former are organised according to traditional patterns of academic behaviour, the latter are driven by outside rationales from the realm of policy-making or commercial applications. Interdisciplines are characterised by porous boundaries and a collective interest in problem-solving (Frickel 2004)—it is possible to think of problems coming from realms outside academia. All this suggests that there is more to scientific communities than the production of knowledge.

As we shall see later, the analysis of collectives in synthetic biology also raises doubts as to whether it is only the production of knowledge that is constitutive for technoscientific communities. The case also helps to specify the relationship between communities and collaborative networks.

\subsubsection{Communities and Collaboration}

If scientific communities are characterised by a decentralised production of knowledge (Gläser 2006), inter-institutional research collaborations (cf. Katz and Martin 1997) represent one kind of this decentralised production. This variety seems to be particularly important in fields of research that bridge traditional disciplinary boundaries. ${ }^{3}$ In interdisciplinary settings, organisationally less integrated modes of production might not be effective (e.g. because researchers in one field do not attend conferences or refer to literature from the respective other field). Collaboration in inter-institutional teams is thus not only relevant for maintaining existing communities of decentralised knowledge production (in a context of growing internationalisation and projectification), but it is also a prime mode of knowledge production for interdisciplinary communities-in-the-making. What remains unclear is whether there is a distinct point where interdisciplinary collaborations spanning several institutions and communities turn into a newly consolidated disciplinary community.

\subsubsection{Interdisciplinary Communities}

In the literature on interdisciplinarity and field-creation, the concept of the interdiscipline (Frickel 2004) provides a useful conceptual angle to think about the

\footnotetext{
${ }^{3}$ Rhoten et al. (2009) identify team collaboration as one among four types of interdisciplinary practices, the others being cross-fertilisation, problem-orientation, and field-creation.
} 
links between interdisciplinary collaborations and scientific communities. Interdisciplines are stabilised disciplinary hybrids that result from the collective action of scientific and intellectual movements (SIMs). They are characterised by the perforation of existing epistemic and institutional boundaries or the invention of new porous ones. They 'tend to exhibit ... organisational, economic and epistemological variability. Disciplines tend to be anchored in university departments and maintain tight control of ... the production and employment of Ph.D. students.... Interdisciplines are more likely to be located in less powerful (and thus less stable) institutes, centres, or programmes' (ibid., p. 273). Recurring formal and informal inter-institutional collaborations are an example of these less stable interdisciplinelike arrangements.

The activities of proponents of a field like synthetic biology (cf. BensaudeVincent 2013) provide the collective action framing required for interdiscipline formation. Researchers promote synthetic biology as a new and engineering-inspired way of thinking about organic systems. Policy-makers decide to set up funding schemes with the synthetic biology label. Both researchers and research funders engage in community-building.

The notion of interdiscipline provides an alternative to asking whether synthetic biology is or will ultimately become a disciplinary community. Its focus on porous boundaries, frame alignment efforts, and temporal arrangements seems particularly helpful to conceptualise collectives in the technosciences. However, as we shall see, the concept of interdiscipline is not enough to understand what is going on in synthetic biology.

While interdiscipline-like structures emerge in some places, in others there is no indication for community beyond what has been called community-making devices. '[C]ommunity-making devices ... help make, or at least articulate the need for, community' (Molyneux-Hodgson and Meyer 2009, p. 139). They can include workshops, conferences, or journals. The specific community-making devices in synthetic biology will be my first empiric entry-point for conceptualising collectivity in synthetic biology. Before that, however, I will briefly introduce the methodological background of the following analyses.

\subsection{Method}

My engagement with the field of synthetic biology started in 2008 when I was a research intern at the Austrian Academy of Sciences' Institute of Technology Assessment (ITA). ITA had a project (COSY) that was investigating the communication and perception of synthetic biology in a variety of publics. In COSY and a related EU project (SYNBIOSAFE), we were focussing on accounts of the ethical and social implications of synthetic biology. My document analyses of relevant publications and the informal discussions with the project PI brought me closer to the discourses around the label of synthetic biology. Ever since this project work, I have 
been following the field, first loosely through contract work for ITA, then as part of my PhD work (2011-2017).

Apart from document analyses and the involvement in social science reflections on synthetic biology, the data basis for the present article comprises 15 semistructured, theory-generating expert interviews (Bogner and Menz 2009). They were conducted between 2014 and 2016 with synthetic biology researchers (PIs and postdocs) in Austria, Germany, Singapore, and the UK. They have been selected to cover institutional, national, and supranational (European) funding environments for synthetic biology. Most interviews took place in the researchers' offices. The interview strategy I chose was to appear as an interested layperson with regard to the science (the synthetic biology research) and a co-expert with regard to science organisation (funding schemes, policies, etc.), which was possible because of prior research. Using co-authored publications as a conversational anchor at the beginning of the interviews, I invited the interviewees to speak about their experiences in interinstitutional collaborations.

These collaborations, heuristically speaking, are an intermediate layer connecting individual with collective practices. They are one site to observe the significance of collectives. Interviews are a suitable method for the research question at hand because the narratives they evoke are part of the discursive-material practices in a given field. 'An interview is not a window on social reality but it is a part, a sample of that reality' (Czarniawska 2004, p. 41).

The interviews were transcribed and analysed following Charmaz' (2006) constructivist version of grounded theory methodology that sees data and the analysis as created in a shared experience of interviewer and interviewee. As became clear in the coding process, it is particularly the interviewees' accounts of collaboration challenges that can serve as a heuristic to investigate the relevance of communities for technoscientific research.

\subsection{Synthetic Biology: To Be or Not To Be (a Community)}

\subsubsection{Community-Making}

Synthetic biology has been in the focus of policy-making and funding right after the label re-surfaced in influential review articles in the mid-2000s (e.g. Endy 2005; Benner and Sismour 2005). In line with early success narratives (e.g. the anti-malaria drug artemisinin), synthetic biology became a field that research policy decisionmakers in a variety of countries aimed to nurture strategically. Large-scale public funding was first made available in the US in the form of the multi-university consortium SynBERC (starting in 2006). In Europe, the UK was the first country to mobilise significant public funds. Synthetic biology researchers were closely involved in the design of these public funding instruments. Since 2013, and after the publication of a national synthetic biology roadmap (Technology Strategy Board 
2012), six synthetic biology centres were established at different university locations.

The fact that researchers identified with the label synthetic biology were invited to advise programme development in the UK shows that such community-making already relies on some sort of collective (before the funding expands the community). In the case of synthetic biology, there were indeed some community-making devices that can be considered researcher-driven and that were in place before largescale public funding set in.

The origin stories of the field regularly refer to the Synthetic Biology x.0 conference series that began at MIT in 2004 and internationalised in 2006. The SynBio x.0 conferences are supported by the BioBricks Foundation. The people behind the BioBricks Foundation are also the driving force behind the Registry of Standard Biological Parts and another very visible event series in synthetic biology: the International Genetically Engineered Machine (iGEM) competitions.

The iGEM competition brings together undergraduate student teams to compete for the best design of biological systems. iGEM started in 2003 as a local MIT initiative. In 2004 the competition had participants from five US universities, and in 2005 it became international. The 2016 edition had 5600 participants from 42 countries. iGem has become a kind of community hub that not only brings undergraduates closer to synthetic biology but, according to my interviewees, also serves as a platform for senior researchers in the field to meet

The above-mentioned Registry of Standard Biological Parts and the Standard Biology Open Language (SBOL) used to describe these parts, can both be understood as community-making devices in synthetic biology. SBOL provides a vocabulary, visuals, and a model that help to define the design of DNA components. With the help of SBOL, one group of synthetic biology researchers can define an abstract design of a biological component (e.g. a switch where parts might be left undefined), while another group continues completing unspecified DNA sequences (cf. Galdzicki et al. 2014, p. 548). The designed component might then be 'plugged' into a standardised chassis provided by yet another group of researchers. SBOL and related efforts towards standardisation can be seen as devices that make it easier for a community of researchers to go about knowledge production-oriented collaboration.

iGEM and SBOL are community-making devices specific to synthetic biology. In addition, there are also synthetic biology journals and an increasing number of higher education curricula. These community-making devices specific to synthetic biology raise expectations of a tightly knit community of knowledge production. Is it that simple, however?

\subsubsection{Community, Communities, Interdiscipline?}

The proponents of synthetic biology in the early 2000s can be seen as a scientific and intellectual movement (SIM) establishing an interdiscipline (Jacobs and Frickel 2009). The existence of synthetic biology institutes, centres or programmes at certain 
universities, especially in the UK, further suggests a characterisation as an interdiscipline - i.e. a disciplinary hybrid of less stability than traditional disciplines. The fact that there are synthetic biology MA and PhD programmes at, for instance, UK universities, indicates that the ongoing institutionalisation of synthetic biology might actually point towards a discipline rather than an interdiscipline. However, despite the existence of a SIM, different degrees of institutionalisation, and a number of community-making devices, further evidence suggests that there is no single coherent biology community-there are communities.

While community-making devices like iGEM continue to be popular, some of the early synthetic biology journals have already been shut down. ${ }^{4}$ More importantly, studies on publication output in synthetic biology suggest that divides in epistemic orientations in the field are continually reflected in knowledge production (Raimbault et al. 2016). The most prominent epistemic divide is between more biology-oriented researchers, aiming to understand biological systems, and engineering-oriented researchers, aiming to build biological systems (Kastenhofer 2013). Both groups tend to disagree on the degree of complexity involved. Interviewee $\mathrm{F}$ is a postdoc in a synthetic biology group in Austria:

I mean, there has been quite a lot of critical voice around what one can do and what one actually cannot do, what is too complex.... I mean the whole iGEM and BioBricks idea is.... As a biologist I was always a bit skeptical of the simplicity of the idea. (Interviewee F)

Synthetic biology, thus, can be seen as a contested umbrella term (cf. Rip and Voß 2013). It serves as an anchor for promissory narratives, imaginaries of application and utilisation (in biofuels, pharma, etc), and funding schemes. It is regularly evoked in influential review articles that typically outline research agendas rather than reporting on research findings (cf. Oldham et al. 2012). Thus the label loosely unites researchers whose knowledge production activities, however, are not integrated in terms of the epistemic objectives, ways of producing knowledge and institutional formations.

Synthetic biology researchers might associate with the label in order to access career and funding opportunities. They might take part in some of synthetic biology's community-making devices (publish in journals, participate in iGEM). But they do not usually collaborate in actual research work. With the exception of iGEM, which seems to attract undergraduate teams and supervisors from all sub-communities of synthetic biology knowledge production, devices like the SBOL and the BioBricks Foundation pertain to an engineering-oriented interpretation. My own empirical analysis confirmed a divide in knowledge production activities: those synthetic biologists whose primary epistemic goal was to understand biological systems referred to the engineering-oriented colleagues as an inspiration, as the following passage from my interview with a Germany-based synthetic biology PI shows:

\footnotetext{
${ }^{4}$ IET Synthetic Biology only published one edition in 2007. Systems and Synthetic Biology stopped publishing in 2015.
} 
Well, they polarise. They are engineers ... from the bottom of their heart. They approach biology with a refreshing ingenuousness, and this is certainly important. This is also what stirred up things.... They have been important to get things going, but it is certainly not my corner. (Interviewee B)

There was no evidence, however, that the two groups collaborate with each other at the project level. What unites the field was, thus, the umbrella term and the community-making devices. Synthetic biology is in ongoing emergence (Morrison 2012) because it does not exist as a community beyond dedicated communitymaking activities.

Synthetic biology researchers relate to the umbrella term out of their own interest and self-orientation. The term allows for a rationally motivated adjustment of interests, e.g. in regard to career opportunities before funders or policy-makers. In terms of the traditional sociological theory introduced above, this resembles societal forms of coordination more than communal ones: members of a society "remain separate in spite of everything that unites them" (Tönnies 2001/1887, see above).

This is not to say that communities do not matter in synthetic biology. They do, and we can now specify in more detail how: knowledge production practices of synthetic biology researchers are linked to a variety of disciplinary and interdisciplinary communities instead of one bounded synthetic biology community. What distinguishes the various synthetic biology communities of knowledge production is not exclusively geography or disciplines: each of the communities is international, and each has its way of establishing an interdiscipline. However, not all researchers that associate with the label of synthetic biology share a common object of investigation. They have different ways of producing knowledge (trial and error synthesis, modelling, complexity reduction, etc.), are motivated by different objectives (building life, understanding life), and share information by different means (via the Standard Registry or more traditional academic channels, for instance).

As elsewhere in the life sciences, research in synthetic biology is international and collaborative. However, there are different strands of synthetic biology that do not integrate their knowledge production activities in actual collaborations. Nevertheless, it is enlightening to have a closer look at research collaboration practices in the field. Accounts of collaboration offer a window into the kinds of communities that play a role in synthetic biology research. As we shall see in the next section, accounts of obstacles that researchers encounter in collaborations challenge the sociology of science's focus on knowledge production when thinking about scientific communities. 


\subsection{Challenges in Synthetic Biology Collaboration: Investigating Communities that Matter}

\subsubsection{Challenged Collaboration}

Working together with others on a research problem involves practices that have been analysed in laboratory studies in great detail (e.g. Latour and Woolgar 1986): building an experimental setup, getting equipment to work, documenting data, connecting results to theories, producing text, etc. Different types of interinstitutional collaboration have been described, ranging from mutual stimulation to collaboration involving a division of labour (Laudel 2002). The collaboration I am interested in involves structured or unstructured interactions over space and time, where different researchers engage in similar practices, interact with human and non-human actors, etc. Collaborations are structured interactions between human actors. They are mediated by and mobilising both human and non-human actors.

In what follows, I want to focus on the former type of resistances. I refer to them as collaboration challenges. Researchers' narratives on their practices include accounts of such challenges.

Above, I have alluded to the different epistemic orientations or communities of vision relevant in synthetic biology —one focused on understanding nature, the other on engineering life (Kastenhofer 2013). Challenges from synthetic biology's interdisciplinary setup also arise from differences in the way research results are reported.

One interviewee described differences in publication strategies between biologists and engineers that evoke the image of differing disciplinary communities of scientific knowledge production:

[People] in biology will [pre-]announce their result, and by announcing the result they claim that they are the ones that work on that ... saying 'This is my turf' ... [I]n engineering most of the time you don't announce the result before you have it. You don't say 'I plan to do this', you say [that you] have done this and this is the result'. (Interviewee M)

This account exemplifies challenges that arise in an interdisciplinary field like synthetic biology. Not only are the disciplinary languages and the epistemic orientations (understanding vs building) different. The publication cultures in biology and engineering are also different.

While such differences between biology and engineering might be one of the reasons behind the divides in synthetic biology knowledge production, challenges also exist in actual projectified collaborations. Interviewee I is a mathematician who joined a synthetic biology collaboration at his university as an in-silico modeller. He gives the following account of the work involved in preparing a joint publication with his biology colleagues:

Well, I have produced a draft, and there I have put everything which I found noteworthy, you know, including all the mathematical curiosities. And the biologists meant that this is not interesting to anybody, that it detracts from the message of our studies, that we have to shorten it'. (Interviewee I) 
The researchers engaged in a collaborative epistemic effort had produced results that they then wanted to publish. In this effort to jointly convey to a scholarly audience the new knowledge they had produced, they encountered challenges. The mathematician interviewee felt the need to include detailed information on mathematical procedures and the mathematically most interesting results. He wanted to see these aspects in the main body of the joint article. Biologists argued that this distracts from the core argument, which in their view is biological. The parties ultimately agreed to put the formulae into the annex. This was the solution the interdisciplinary collaborators found in order to have the same article speak to (at least) two different communities. At the root of this challenge are ways of talking about research results that are defined not inside the collaboration but outside it: in communities the researchers belonged to apart from their potential identity as synthetic biologists.

We have seen that after more than a decade of top-down and bottom-up community-making, there is still no single synthetic biology community. The field is not transitioning into a disciplinary community (cf. Cain 2002). It instead can be described as an interdiscipline characterised by porous epistemic boundaries and temporal forms of institutionalisation. Even this character as an interdiscipline is limited to specific science policy environments (the UK, in particular). Researchers relating to the umbrella term synthetic biology have different objectives and forms of knowledge production.

Not only is the way of synthetic biology knowledge production contested. Interview data on research collaborations also reveal that the contexts where (and the forms how) synthetic biology knowledge is applied vary and are contested.

\subsubsection{Communities of Knowledge Application?}

The accounts of synthetic biology researchers presented above point beyond the production of scientific knowledge. The challenges between the biomathematician and the biologists were not so much related to the production of knowledge, but to its dissemination through a joint publication. As we shall see, beyond dissemination, the data also demonstrates how contexts of knowledge application become relevant for technoscientific communities.

What we observe in synthetic biology is a disconnect of communities of knowledge production, communities of dissemination and communities of application. ${ }^{5}$ Researchers come together around synthetic biology-related topics to carry out research, but they report their results to other, more traditional and disciplinary scientific communities. They all attend iGem, but they have very different

\footnotetext{
${ }^{5}$ In line with earlier discussions in the philosophy of science one might speak of the context of discovery (knowledge production), the context of justification (dissemination) and the context of application instead (Reichenbach 1938 for the first two, Meyer-Abich 1988 or Gibbons et al. 1994 for the latter).
} 
application contexts for engineered biology in mind. This is not to say that knowledge production, knowledge dissemination and knowledge application are practices that can be clearly separated from each other. STS research has convincingly shown that they are deeply interrelated. Application perspectives, for instance, affect knowledge production and viceversa (cf. de Laet and Mol 2000; Gibbons et al. 1994). The production and application of knowledge can also be conflated in one and the same collaboration:

I have not had the interaction ... with the modellist that I wanted to have.... [T] here is certainly some drive in synthetic biology ... to create new models ... but that does not seem to be what modellers want to do. They want to continue modelling the organisms that they have the ... I guess that's what they have the data for'. (Interviewee G)

Interviewee $\mathrm{G}$ is a UK-based synthetic biology PI trained in biochemistry. While she wants to engage in knowledge production, the other parties necessary for the collaboration are interested in finding opportunities to apply knowledge they already produced in another context. Interviewee $\mathrm{G}$ herself is interested in knowledge application in an industrial context.

I have worked with [company $\mathrm{x}$ ] on a ... project. [Company $\mathrm{x}$ ] is different... . They have certain synthetic biology tools that they have commercialised... . There is a lot of industry ... meetings that $I$ have had ... that we collaborate with, but we really are providing them with ... a service or knowhow that applies to them in a specific situation. But [company $\mathrm{x}$ ] is quite different. Basically, they are a company that operates almost in the same way as an academic, who is industrially focused'. (Interviewee G)

The application of Interviewee G's knowledge took a specific shape (industryoriented, close to knowledge production) because of a specific local environment (the company having close relationships to her university) and her own trajectory.

My choice of the word application is deliberate. I use it because it encompasses more than the dissemination of research results in journals or the reutilisation of prior work in new research projects. It points beyond the cycles of scientific capitalism as discussed by Knorr-Cetina (1982). Instead, it connects epistemic work to non-epistemically oriented rationales. In synthetic biology, it can entail, for instance, the use of synthetic compounds or processes in the production of biofuels, drugs, or flavours. Institutionally, application can be linked to industry, start-ups, communityspecific environments (e.g. the BioBricks movement) as well as policy. Both the local and institutional environment (university policies regarding industry collaboration, availability of partners, etc) and the individual career paths of researchers play a role in knowledge application. They in turn also shape knowledge production. It is the local community and innovation system that influence how synthetic biology materialises as a field in this specific environment.

Societal applications that can be derived from research results are another possible application context. One interviewee talked about a synthetic biology-based biosensor for arsenic detection in drinking water in rural areas in Bangladesh:

[T]he business plan was that NGOs would essentially use money that's been devoted to this purpose to buy these devices ... and then distribute them.... And another part of the 
prototype that we've been talking about is designing an instruction sheet with pictures and graphics and things explaining how to actually use it'. (Interviewee $\mathrm{H}$ )

Researchers most often choose to publish, but they can also delay publication in order to first file a patent. Or they can look at societal impact and orient publication channels and types accordingly. What researchers choose depends, among other things, on the kind of communities they are part of. Thus, although the practices of knowledge production and application are often interlinked, the communities wherein these activities are embedded are not necessarily the same. Not only do communities of knowledge production affect application (e.g. getting researchers to publish in specific disciplinary journals), but the communities of knowledge application can affect knowledge production.

Proposing knowledge application as a relevant analytical anchor point mirrors the observation in technoscience-oriented STS literature that scientific research and technological development are no longer separated. Similar observations have been made regarding societal impact or commercialisation: observers of developments in higher education speak about the 'entrepreneurial university', particularly in the area of biotechnology (Yi 2015). Societal impact is a relevant dimension in research as evidenced by large-scale institutionalised performance assessments. Researchers have to think about applications and impact when applying for funds and, increasingly, when advancing their careers. In light of these developments, it seems necessary to consider communities of knowledge application.

Borrowing from, but expanding definitions of epistemic communities, ${ }^{6}$ communities of knowledge application could be defined as work communities concerned with the application of certain types of knowledge. Communities of knowledge application might be closely related to communities of knowledge production (e.g. when researchers' publications in journals are referred to in the production of new knowledge), but they can also be separate (e.g. when researchers join collectives of technology transfer professionals at the university and beyond).

I am not claiming that the work researchers undertake with regard to the application of knowledge is always organised in communities. On the contrary, parts of my data show that they sometimes actively refuse to access certain communities and their practices, for instance when it comes to the commercial exploitation of research results:

Back in $[\mathrm{x}]^{\text {'s }}$ lab I was working also with someone to patent ... and then we realised it's just so much effort.... It takes so much of our time ... and it will delay our publication'. (Interviewee F)

Others have also shown that researchers sometimes see the private sector as simply another venue for knowledge production (Fochler 2016). However, there are discussions on new types of scientists that can be related to communities these

\footnotetext{
${ }^{6}$ Continuing the use of the label community as it was introduced in the sociology of science (different from traditional sociological theory); this choice is justified by two reasons: one is that it allows the concept to remain visibly related to the notion of communities of knowledge production; the other reason will become clear below.
} 
scientists belong to. Lam (2010), for instance, describes 'entrepreneurial scientists' and 'entrepreneurial hybrids' that embrace commercial application of knowledge results. ${ }^{7}$ In his research on entrepreneurial scientists, Gulbrandsen (2005) argues that these are not part of the academic and the entrepreneurial world, but of none of these worlds. They are what he calls 'liminal scientists' with a certain distance to both worlds. He does not address the question as to whether there is a community of application made up of liminal scientists. Further research is required to clarify whether the commercial application of results of technoscientific research is driven by individuals who identify with academia, entrepreneurship, both, or none of these worlds.

Knowledge production, dissemination and application are entangled in everyday practices. Nevertheless, it is useful to sharpen our heuristic and conceptual tools to be able to distinguish communities oriented towards knowledge production from those more oriented towards application. Technoscientists are not necessarily 'only' knowledge producers.

\subsection{Conclusion}

In the present article, I have used my own empirical material from the case of synthetic biology to critically reflect on the notion of scientific community. The case proves Meyer and Molyneux-Hodgson (2010) right when they state that '[s] cientific communities matter' - with a strong emphasis on the plural form: researchers who identify with the field of synthetic biology do not necessarily have a common way of producing knowledge. Instead of one consolidated and bounded community, there are multiple communities of synthetic biology knowledge production and application. Synthetic biology thus is an umbrella term, advertising innovative research paradigms and collaboration modes at the intersection of the life sciences, chemistry, physics, mathematics, and computer science. It also designates a set of community-making devices, reflecting strategies of a purposeful steering of scientific development.

But how can we further specify the character of this 'communality in the plural'? We have seen that parts of the synthetic biology landscape can be described as an interdiscipline (Frickel 2004). The field is institutionalised in a temporary fashion in centres, institutes, and degree programmes. As Kastenhofer and Molyneux Hodgson write in the introduction to this volume, it is a field that seems to be stabilised by forces external to the epistemic enterprise. It is stabilised by funding, by the iGem competitions, and by promissory narratives. The transgression of professional identities that was at the foundation of synthetic biology - being an engineer, but doing biology -does not exclude researchers with more traditional disciplinary identities to engage with the label. Synthetic biology keeps maintaining porous boundaries

\footnotetext{
${ }^{7}$ We find several of these hybrids among the early proponents of synthetic biology.
} 
between different disciplines and identity options. However, the boundaries between the different techno-epistemic orientations (understanding nature and engineering life) as well as the different ways and means to produce knowledge under the label of synthetic biology seem surprisingly stable. This suggests that the field, despite all community-making efforts, is not transitioning towards a consolidated disciplinary community.

The analysis of the synthetic biology case illustrates two further aspects that are not sufficiently accommodated in Frickel's notion of an interdiscipline. First, contexts of knowledge application also have to be accommodated in technoscientific interdisciplines. Their relation to knowledge production has to be negotiated. Porous boundaries are not only needed between disciplines, their methods, concepts, and theories. They also have to be established and maintained between academic and non-academic actors. In this sense, the local (organisational, geographical) contexts matter: it makes a difference whether a synthetic biology interdiscipline takes shape in an environment of potential private sector investors, in a virtual community of biohackers, or in development cooperation networks.

Under the umbrella term synthetic biology, we observe researchers sharing views on knowledge application while differing in their outlook on knowledge production. At the same time, researchers with the same epistemic orientation in their knowledge production can differ in their outlook on knowledge application. Being aware of this diversification in communities of scientific practice is important because of the increased relevance of knowledge application for science policy, research funders, ${ }^{8}$ and science's public image.

The special relevance of application within synthetic biology brings us to the second aspect of the notion of interdiscipline that my analysis problematised. Frickel stated that interdisciplines 'are more likely to be located in less powerful ... institutes, centres, or programmes and do not enjoy control of internalized markets' (ibid., p. 273). The significant funds invested in synthetic biology, together with broader trends towards third-party funding, mission-orientation, and projectification, call our attention to a paradox: interdisciplines linked to umbrella terms are more fragile in an academic institutional environment, but at the same time, within contemporary innovation regimes, these same interdisciplines become important to obtain the very resources the academic environment is built upon.

The case of synthetic biology demonstrates that both, contexts of knowledge production and contexts of knowledge application, should be taken into account in an analysis of technoscientific communities. Communities can form around epistemic practices as well as around practices of application. The identities of researchers in general and in the technosciences in particular can even centre on the application of the knowledge they produce. Researchers might increasingly be part not only of one or several (inter-)disciplinary communities but of communities oriented towards

\footnotetext{
${ }^{8}$ E.g. in the context of the EU Research and Innovation Framework Programmes that concede specific importance not only to the dissemination, but, as it is currently called, the exploitation of knowledge.
} 
knowledge application. While this might still be an exception, developments in research funding suggest it could become a rule in the future. Thinking about communities of both knowledge production and application allows us to grasp potential changes in the collectives (and related identities) relevant to technoscientists.

Acknowledgements The author wants to thank Karen Kastenhofer and two anonymous reviewers for valuable feedback.

\section{References}

Benner, S.A., and A.M. Sismour. 2005. Synthetic biology. Nature Reviews Genetics 6: 533-543.

Bensaude-Vincent, B. 2013. Discipline-building in synthetic biology. Studies in History and Philosophy of Biological and Biomedical Sciences 44: 122-129.

Bogner, A., and W. Menz. 2009. The theory-generating expert interview: Epistemological interest, forms of knowledge, interaction. In Interviewing Experts, ed. A. Bogner, B. Littig, and W. Menz, 32-80. Basingstoke/New York: Palgrave Macmillan.

Böhme, G. 1974. Die soziale Bedeutung kognitiver Strukturen: Ein handlungstheoretisches Konzept der scientific community. Soziale Welt 25 (2): 188-208.

Calvert, J. 2010. Synthetic biology: Constructing nature? The Sociological Review 58: 95-112.

Cain, J. 2002. Epistemic and community transition in American evolutionary studies: The Committee on Common Problems of Genetics, Paleontology, and Systematics (1942-1949). Studies in History and Philosophy of Biological and Biomedical Sciences 33 (2): 283-313.

Charmaz, K. 2006. Constructing grounded theory. London/Thousand Oaks/New Delhi: Sage.

Czarniawska, B. 2004. Narratives in social science research. London/Thousand Oaks/New Delhi: Sage.

De Laet, M., and A. Mol. 2000. The Zimbabwe bush pump. Mechanics of a fluid technology. Social Studies of Science 30 (2): 225-263.

Elzinga, A. 1993. Science as the continuation of politics by other means. In Controversial science. From content to contention, ed. T. Brante, S. Fuller, and W. Lynch, 127-152. Albany: State University New York Press.

Endy, D. 2005. Foundations for engineering biology. Nature 438: 449-453.

European Commission. 2005. Synthetic biology. Applying engineering to biology. Report of a NEST high-level expert group. Technical report. Brussels: European Commission DirectorateGeneral for Research.

Fleck, L. 1981. Genesis and development of a scientific fact. Chicago: University of Chicago Press. (Original work published 1935.).

Fochler, M. 2016. Beyond and between academia and business: How Austrian biotechnology researchers describe high-tech startup companies as spaces of knowledge production. Social Studies of Science 46 (2): 259-281.

Frickel, S. 2004. Building an interdiscipline: Collective action framing and the rise of genetic toxicology. Social Problems 51 (2): 269-287.

Galdzicki, M., et al. 2014. The Synthetic Biology Open Language (SBOL) provides a community standard for communicating designs in synthetic biology. Nature Biotechnology 32: 545-550.

Gibbons, Michael, et al. 1994. The new production of knowledge: The dynamics of science and research in contemporary societies. London: Sage.

Gläser, J. 2006. Wissenschaftliche Produktionsgemeinschaften. Die soziale Ordnung der Forschung. Frankfurt/New York: Campus. 
Gulbrandsen, M. 2005. 'But Peter's in it for the money'-The liminality of entrepreneurial scientists. VEST Journal for Science and Technology Studies 18 (1/2): 49-75.

Holzner, B., and J. Marx. 1979. Knowledge affiliation: The knowledge system in society. Boston: Allyn and Bacon.

Jacobs, Jerry A., and Scott Frickel. 2009. Interdisciplinarity: A critical assessment. Annual Review of Sociology 35 (1): 43-65.

Kastenhofer, K. 2018. Community and identity in contemporary technosciences: Conceptual issues and empirical change. EASST Review, 37(2). https://easst.net/article/community-and-identityin-contemporary-technosciences-conceptual-issues-and-empirical-change/. Accessed $28 \mathrm{Apr}$ 2018.

2013. Two sides of the same coin? The (techno)epistemic cultures of systems and synthetic biology. Studies in History and Philosophy of Biological and Biomedical Sciences 44: 130-140.

- 2009. Debating the risks and ethics of emerging technosciences. Innovation: The European Journal of Social Science Research 22 (1): 77-103.

Katz, J.S., and B.R. Martin. 1997. What is research collaboration? Research Policy 26: 1-18.

Knorr-Cetina, K. 1982. Scientific communities or transepistemic arenas of research? A critique of quasi-economic models of science. Social Studies of Science 12: 101-130.

. 1981. The manufacture of knowledge. An essay on the constructivist and contextual nature of science. Oxford: Pergamon Press.

Kuhn, T. 1962/2002. The structure of scientific revolutions. Chicago: University of Chicago Press.

Lam, A. 2010. From 'ivory tower traditionalists' to 'entrepreneurial scientists'? Academic scientists in fuzzy university-industry boundaries. Social Studies of Science 40 (2): 307-340.

Latour, B., and S. Woolgar. 1986. Laboratory life. The construction of scientific facts. Princeton: Princeton University Press.

Laudel, G. 2002. Collaboration and reward. What do we measure by co-authorships? Research Evaluation 11 (1): 3-15.

Marcovich, A., and T. Shinn. 2011. Where is disciplinarity going? Meeting on the boarderland. Social Science Information 50 (3-4): 582-606.

Merton, R.K. 1993. The sociology of science: Theoretical and empirical investigations. Chicago: University of Chicago Press. (Original work published 1942.)

Meyer, M., and S. Molyneux-Hodgson. 2010. Introduction: The dynamics of epistemic communities. Sociological Research Online, 15(2), 14. http://www.socresonline.org.uk/15/2/14.html. Accessed 30 Oct 2017.

Meyer-Abich, K.M. 1988. Wissenschaft für die Zukunft. Holistisches Denken in ökologischer und gesellschaftlicher Verantwortung. München: Beck.

Molyneux-Hodgson, S., and M. Meyer. 2009. Tales of emergence-Synthetic biology as a scientific community in the making. BioSocieties 4 (2-2): 129-145.

Morrison, M. 2012. Promissory futures and possible pasts: The dynamics of contemporary expectations in regenerative medicine. BioSocieties 7 (1): 3-22.

Nordmann, A. 2011. The age of technoscience. In Science transformed? Debating claims of an epochal break, ed. A. Nordmann, H. Radder, and G. Schiemann, 19-30. Pittsburgh: Pittsburgh University Press.

O’Malley, M.A., et al. 2007. Knowledge-making distinctions in synthetic biology. BioEssays 30: $57-65$.

Oldham, P., S. Hall, and G. Burton. 2012. Synthetic biology: Mapping the scientific landscape. PLoS One 7 (4): e34368.

Parsons, T., and E. Shils, eds. 1951. Toward a general theory of action. Cambridge, MA: Harvard University Press.

Polanyi, M. 1962. Personal knowledge. Towards a post-critical philosophy. London: Routledge.

Raimbault, B., J.-P. Cointet, and P.-B. Joly. 2016. Mapping the emergence of synthetic biology. PLoS One 11 (9): e0161522.

Reichenbach, H. 1938. Experience and prediction. An analysis of the foundations and the structure of knowledge. Chicago: University of Chicago Press. 
Rhoten, D., E. O'Connor, and E.J. Hackett. 2009. The act of collaborative creation and the art of integrative creativity: Originality, disciplinarity and interdisciplinarity. Thesis Eleven 96 (1): $83-108$.

Rip, A., and J.-P. Voß. 2013. Umbrella terms as mediators in the governance of emerging science and technology. Science, Technology \& Innovation Studies 9 (2): 39-59.

Schmidt, M., et al., eds. 2010. Synthetic biology. The technoscience and its societal consequences. Dordrecht: Springer.

Swidler, A. 2001. What anchors cultural practices. In The practice turn in contemporary theory, ed. T.R. Schatzki, K. Knorr Cetina, and E. von Savigny, 83-100. London/New York: Routledge.

Technology Strategy Board. 2012. A synthetic biology roadmap for the UK. https://webarchive. nationalarchives.gov.uk/20130302042701/http://www.innovateuk.org/_assets/tsb_ syntheticbiologyroadmap.pdf. Accessed 31 Jan 2019.

Tönnies, F. 2001. Community and civil society. Cambridge: Cambridge University Press. (Original work published 1887).

Weber, M. 1978. Economy and society. Berkeley/Los Angeles: University of California Press. (Original work published 1921).

Whitley, R. 1978. Types of science, organizational strategies and patterns of work in research laboratories in different scientific fields. Social Science Information 17 (3): 427-447.

Yi, D. 2015. The recombinant university: Genetic engineering and the emergence of Stanford biotechnology. Chicago: University of Chicago Press.

Open Access This chapter is licensed under the terms of the Creative Commons Attribution 4.0 International License (http://creativecommons.org/licenses/by/4.0/), which permits use, sharing, adaptation, distribution and reproduction in any medium or format, as long as you give appropriate credit to the original author(s) and the source, provide a link to the Creative Commons license and indicate if changes were made.

The images or other third party material in this chapter are included in the chapter's Creative Commons license, unless indicated otherwise in a credit line to the material. If material is not included in the chapter's Creative Commons license and your intended use is not permitted by statutory regulation or exceeds the permitted use, you will need to obtain permission directly from the copyright holder.

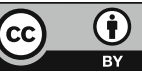

